\title{
Caring is Masculine: Stay-at-Home Fathers and Masculine Identity
}

\author{
Joyce Y. Lee and Shawna J. Lee \\ University of Michigan, Ann Arbor, Michigan
}

\begin{abstract}
This qualitative study examined 25 stay-at-home fathers (SAHFs) in the United States and their lived experiences through the perspective of the theory of caring masculinities. Results from semistructured telephone interviews demonstrated that the majority of SAHFs voluntarily opted to be full-time caregivers, named financial reasons for becoming a SAHF, reported high levels of satisfaction in caring for their children, and experienced little change in their relationship with their spouse or partner as a result of being a SAHF. Major findings included the potential change in attitudes and masculine identities that accompany becoming a SAHF, men's emotional connection with others, and their increased respect for caregiving. Overall, SAHFs reported incorporating aspects of masculine and feminine qualities to develop a new masculine identity that best supports their caregiving role and experiences. In addition, SAHFs identified social isolation and mixed reactions from people as the 2 main challenges against constructing and maintaining their new masculinity; they also reported support from multiple social networks (e.g., partners, female family members, other SAHFs) as a means to successfully overcome such challenges. The results are further discussed in the context of the caring masculinities framework and suggestions are provided for future research.
\end{abstract}

Keywords: men, masculinity, fatherhood, stay-at-home fathers, caring masculinities

The last three decades have witnessed significant changes in the balance of work and family life for men and women in the United States. Between 1972 and 2012, working age women's labor participation rate increased from $43.9 \%$ to $57.7 \%$, whereas working age men's labor participation rate decreased from $78.9 \%$ to $70.2 \%$ (U.S. Bureau of Labor Statistics, 2014). In 2015, over two thirds $(64.2 \%)$ of women with children under age 6 and over half $(58.1 \%)$ of women with infants under age 1 were working (U.S. Bureau of Labor Statistics, 2016). With an increase in the number of mothers in the workforce, the number of stay-at-home mothers declined during the same time period; in 1972, approximately $47 \%$ of married mothers were stay-at-home mothers, compared with 29\% in 2012 (Cohn, Livingston, \& Wang, 2014; Galley, 2014). In sum, the large percentage of women with young children working is a notable shift from earlier decades when mothers were much less likely to be working and much more likely to be primary caregivers of children.

Overall, the increasing number of mothers in the labor force has not resulted in dramatic increases in the number of fathers who are primary caregivers of young children. The U.S. Census defines

This article was published Online First October 6, 2016.

Joyce Y. Lee and Shawna J. Lee, School of Social Work, University of Michigan, Ann Arbor, Michigan.

We thank the fathers who participated in this study and the National At-Home Dad Network. Some of the data and ideas appearing in this article were presented on March, 2016, at the Annual Conference on Men and Masculinities of the American Men's Studies Association in Ann Arbor, Michigan. The abstract of the article is shared on the Shawna J. Lee's website: www.parentingincontext.org

Correspondence concerning this article should be addressed to Joyce Y. Lee, School of Social Work, University of Michigan, 1080 South University Avenue, Ann Arbor, MI 48109. E-mail: joyceyl@umich.edu stay-at-home fathers (SAHFs) as married men with children younger than 15-years-old and who remained out of the labor force for at least 1 year to primarily care for their children while their wives worked outside of the home (U.S. Census Bureau, 2015). Census data show that although the number of SAHFs more than doubled from 93,000 in 2000 to 211,000 in 2014 (U.S. Census Bureau, 2015), mothers are still the large majority of full-time caregivers. In 2012, about $84 \%$ of stay-at-home parents were mothers and $16 \%$ were fathers (Livingston, 2014).

Sources that use broader parameters to define a SAHF report larger numbers. A Pew Research Center report by Livingston (2014) included fathers of older children (e.g., younger than 18years-old), additional relationship statuses (e.g., cohabiting and married), and fathers who did not work for pay in the prior year, regardless of the reason. Using these parameters, the number of SAHFs existing in 2012 was calculated to be approximately 2 million. Latshaw (2011) used a combination of in-depth interviews and microdata from the 2005-2007 American Community Survey to reestimate the Census's count of SAHFs and found that the Census may underestimate the number of SAHFs by as many as 1.4 million because the Census estimate does not count SAHFs who worked part-time, reported other reasons for being home, or had been home less than 1 year (Latshaw, 2011).

In addition to the growing number of SAHFs, data show that in general fathers are spending more time caring for their children regardless of their employment status. With societal shifts in gender roles and increased attention to fathers' involvement in childcare, fathers are assuming greater roles in raising their children (National Academies of Sciences, Engineering, \& Medicine, 2016). They are increasingly engaged in activities that involve preparing and eating meals with their children, reading and talking to them, playing with them, and helping them with homework (Bianchi, Robinson, \& Milkie, 2007; Cabrera, Hofferth, \& Chae, 
2011; Jones \& Mosher, 2013; Livingston \& Parker, 2011). Moreover, fathers have nearly tripled their time spent with children in the average week, from about $2.5 \mathrm{hr}$ per week in 1965 to $7.3 \mathrm{hr}$ per week in 2011 (Parker \& Wang, 2013). Fathers today spend more time in unpaid work than ever before. The amount of work time fathers put into housework and caring for children has increased from $14 \%$ in $1965 \%$ to $31 \%$ in 2011 (Parker \& Wang, 2013).

Although the number of SAHFs is increasing and fathers in general are spending more time caring for their children and doing housework, an important distinction to note is the differential care work and household tasks with which men and women engage. According to the American Time Use Survey (U.S. Bureau of Labor Statistics, 2015a), for the combined years of 2010 and 2014, women spent on average 35.4 min per day and men spent on average $13.2 \mathrm{~min}$ per day physically caring for children under the age of 18. During the same years, men spent on average $4.8 \mathrm{~min}$ per day and women spent on average $4.2 \mathrm{~min}$ per day playing or doing hobbies with the youngest child between the ages of 6 and 17 (U.S. Bureau of Labor Statistics, 2015a). Although time difference in playing or doing hobbies is marginal between men and women, it still points to the different types of care work men and women do on average for their children (i.e., women doing more physical care work than men and men engaging in slightly more play than women).

With respect to housework, on an average day in 2014, women spent more than twice as much time preparing meals and cleaning and four times as much time doing laundry as did men (U.S. Bureau of Labor Statistics, 2015b). During the same year, men spent more than twice as much time doing lawn and garden work, interior and exterior maintenance, and repairs as did women (U.S. Bureau of Labor Statistics, 2015b). These differences in care and household work can be explained using Hanlon's (2012) reference to men as "care commanders" and women as "care foot soldiers." Hanlon (2012) argued that men are more likely than women to make overarching decisions about caring and mainly get involved in significant events; therefore, men are called "care commanders." Women are more likely than men to engage in everyday work of caring, and therefore called "care foot soldiers." In Hanlon's (2012) view, gender difference in care and household work represents an unbalanced power distribution in private life where status in the family determines one's role in the family division of labor.

Despite the unequal division of labor at home, it is important to acknowledge that, as mentioned earlier, men are spending more time doing housework and caring for their children than ever before and that the number of SAHFs is at an all time high. Two socioeconomic factors-the growth of women's educational achievement and the impact of the Great Recession in 2008 on paternal employment- have contributed to the increasing number of fathers staying home to care for their young children while their spouse or partner earn the family income (Yogman \& Garfield, 2016). As the number of SAHFs grow, the critical role they play in childcare is evidenced in the fact that they care for more than 200,000 children full-time and almost 2 million preschoolers parttime (Yogman \& Garfield, 2016).

Previous studies have also found that men become SAHFs for various reasons. The most common reason cited by American fathers (Rochlen, McKelley, \& Whittaker, 2010; Rochlen, Suizzo, McKelley, \& Scaringi, 2008; Solomon, 2014a; Zimmerman, 2000) and Belgian fathers (Doucet \& Merla, 2007; Merla, 2008) had to do with their female spouse or partner's career (i.e., she had better pay), the belief that at least one parent should stay home to care for the child, and the fact that they are a "better fit" to stay home than their female spouse or partner. Among Canadian fathers, Doucet (2004) found that having flexible work schedules (i.e., work from home) and being between jobs (e.g., lost job or unhappy with career) were the two most common reasons reported for becoming a SAHF.

Fischer and Anderson's (2012) study provided further nuance behind men's reasons for becoming a SAHF. They found that wanting to be a SAHF is the most important reason for staying home. In addition, the more important men's female partner was in influencing their decisions to become a SAHF, the lower the levels of men's masculine characteristics and the more enjoyment they reported in being a SAHF. In Solomon's (2014a) study, a factor that helped men choose to become SAHFs was that most of them viewed themselves as interchangeable with their wives. In other words, these SAHFs understood parenting as a gender-neutral task.

Given the broader demographic factors influencing men's decisions to become primary caregivers, we sought to understand SAHFs' lived experiences with a focus on how becoming a SAHF might contribute to shifts in men's perceptions of masculinity. We also examined the challenges of being a male primary caregiver and how SAHFs navigate those challenges. In the following section, we outline empirical work and theoretical frameworks that collectively suggest the gendered nature of early caregiving-a context that is likely to make the transition to becoming a SAHF challenging. Next, we introduce caring masculinities (Elliott, 2015) as our guiding framework and describe how its use in our study extends prior research on SAHFs. Finally, we explain how we used grounded theory (Glaser \& Strauss, 1965; Strauss \& Corbin, 1990) to extract and analyze themes relevant to the major goals of this study.

\section{The Gendered Nature of Early Caregiving}

\section{Caregiving as a Traditionally Feminine Domain}

Questions about masculine identity and how SAHFs navigate caregiving are interesting for several reasons. As noted above, while there is no question that more mothers of young children are working than ever before, and men are spending more time caring for children, the gendered nature of early caregiving has not shifted dramatically. Put another way, caregiving - particularly of young children-is often viewed as a feminine domain and highly gendered toward maternal involvement. This view is consistent with studies that examined unpaid care work and found that women provided many more hours of unpaid child care and housework than men (Fine \& Glendinning, 2005; Ungerson, 2006).

Extending this concept of gendered nature of care to SAHFs, Rochlen, McKelley, and Whittaker (2010) explored 207 SAHFs' perceptions of incidences of stigma. They found that of those fathers who reported stigma (approximately half of the sample), $70 \%$ attributed incidents of stigma to stay-at-home mothers; SAHFs reported that many of these incidents occurred on the playground and left them feeling isolated. Latshaw (2011) demonstrated similar findings among 40 SAHFs, many of whom reported difficulty being accepted into mothers' playgroups and 
feeling "awkward" asking mothers to spend time one-one-one. Consequently, many SAHFs reported spending long hours at home without substantial adult interaction. These studies underscore the notion that places where stay-at-home parents congregate are gendered toward maternal care, and that SAHFs navigate a challenging environment to be accepted as primary caregivers.

\section{Traditionally Masculine Practices and Roles}

Whereas women were traditionally viewed as the primary caregivers of children, Connell's (1995, 2000) hegemonic masculinity describes how gender practices necessitate that men achieve ascendancy, especially over women, and establish a hierarchical gender order (Connell \& Messerschmidt, 2005; Elliott, 2015). Closely linked is the notion of men as the head of household, family protector, and financial provider, or primary breadwinner (Pleck, 1995). Gender role strain (Garnets \& Pleck, 1979; Pleck, 1981, 1995) would suggest that conforming to restrictive gender roles, such as those described in the hegemonic masculinity framework, can be detrimental to well-being in part because feelings of inadequacy may arise when one fails to live up to traditional gender ideals (Freitag, 2004). Furthermore, gender role conflict restricts one's potential and devalues behaviors that are perceived as nongender conforming (O’Neil, Good, \& Holmes, 1995; Pleck, Sonenstein, \& Ku, 1993; Thompson \& Pleck, 1995). Pleck further argues that strict adherence to notions of masculinity ideology can disrupt men's interpersonal relationships (Pleck, 1995).

A key point is the link between paid work and masculinity, an ideology that is historically rooted in institutions that assumed men were primary breadwinners (Crompton, 2006; Kimmel, 1993; Lewis, 1992). Even though in most modern two-parent families both men and women work, research suggests that the importance of the breadwinner status to men's masculine identities remains strong (Thébaud, 2010; Tichenor, 2005). For example, Gerson (1993) found that men with employed wives reported that they felt the need to be the primary breadwinner. Tichenor (2005) examined couples where the women earned more than the men and found that men still perceived their work to be more important than their partner's work. Other studies have found that even when their wife's income was comparable with theirs, men tended to interpret their employment as providing for the essential needs of the family, whereas their wife's income was considered supplemental (Ferree, 1994; Moen \& Sweet, 2003; Potuchek, 1997; Raley, Mattingly, \& Bianchi, 2006).

\section{Guiding Theoretical Framework: Caring Masculinities}

The concept of caring masculinities (Elliott, 2015) provides an alternative vantage point from which to consider traditional gender roles and practices. Elliott draws substantially on the works of Hanlon (2012) who, by examining Irish men's caregiving in the home, demonstrated that masculinities, values of care, and emotions are intertwined. Hanlon (2012) found in his study that doing care work is associated with men's development of flexible definitions of masculinity, other-centered sensibilities, expressions of vulnerability, and appreciation for care work. Based on Hanlon's (2012) work, Elliott (2015) argues that engaging in care work helps men develop caring forms of masculinities and nurturing identities.
Elliott (2015) then identifies three main characteristics of caring masculinities. The first is rejecting domination. Because domination leads to inequality in a relationship, caring masculinities argues for an absence of domination to ensure the presence of equality. Men who adopt caring masculinities are asked to become "disloyal" to traditional masculine norms, especially those that are synonymous with domination or violence. The second characteristic is valuing positive emotions and emphasizing affective, relational, emotional, and interdependent qualities of care. In so doing, caring masculinities contrasts with traditional masculinities that endorse emotional stoicisms; men are to not feel and if by chance they do-especially hurt and pain-they should suppress those feelings and hope they go away (hooks, 2004). The third and final characteristic of caring masculinities is recasting traditional masculine values (i.e., emphasis on men as the head of household, protector, or breadwinner) into relational, interdependent, and care-oriented values. For example, "responsibility" can be looking after one's children perhaps in addition to or instead of being a financial provider. Overall, caring masculinities introduce relational and caregiving qualities to traditional masculine identities, yielding new meanings for men who adopt caring masculinities.

Because caring masculinities emphasize caregiving roles as neither being inherently male nor female, SAHFs are an excellent population with which to consider how masculinities change. Men who become SAHFs may do so for a variety of reasons, including job loss, unemployment, under employment, or to balance workfamily strain (Chesley, 2011; Dunn, Rochlen, \& O'Brien, 2011). Some may voluntarily "opt in" to caregiving because of personal preferences and desires to be a primary caregiver (Fischer \& Anderson, 2012). No matter the impetus for men's influx into this role, there is reason to believe that the primary caregiving role may contribute to new viewpoints that emphasize the interconnectedness of caring and masculinity (Doucet, 2004). As a case in point, research has found that SAHFs are acutely aware of traditional masculine stereotypies and do not necessarily differ from employed fathers in their level of traditional masculine characteristics (Fischer \& Anderson, 2012; Rochlen et al., 2008). At the same time, SAHFs report lower adherence to traditional gender role attitudes compared to employed fathers (Fischer \& Anderson, 2012).

In this study, we extend prior research on SAHFs (Doucet, 2004; Fischer \& Anderson, 2012; Rochlen et al., 2010; Rochlen et al., 2008; Solomon, 2014a) primarily by examining SAHFs from the caring masculinities framework (Elliott, 2015). More specifically, we investigate how SAHFs perceive traditional masculine identities and norms, construct alternative masculine identities within a nontraditional caregiving context, and navigate the challenges of constructing and maintaining their new masculine identities in a female-gendered world of parenting. We explore the unique challenges SAHFs face, including feelings of social isolation. In addition, we describe men's reasons for becoming SAHFs and how being a SAHF impacted changes in the relationship quality with their spouse or partner and children.

\section{Grounded Theory}

We used grounded theory (Glaser \& Strauss, 1965; Strauss \& Corbin, 1990) to analyze SAHFs' narratives of their caregiving experiences. Grounded theory is an inductive methodological ap- 
proach in which the application of theoretical understanding of phenomena is grounded in data. In grounded theory, researchers typically do not have a priori hypotheses at the start of the study, as was the case in the current study; rather, researchers use coding and textual analysis to find and categorize themes, as well as identify relevant theoretical constructs based on interpretation of data.

The coding procedure is key in the grounded theory method. Data analysis begins with breaking the data into concepts (i.e., open coding). Then, the concepts are organized into categories (i.e., axial coding). Next, the relationships between these categories are identified (i.e., selective or theoretical coding), thus building a theory "from the data up." Finally, the researcher compares emerging concepts throughout the study, discovering additional relationships between concepts. This constant comparison contributes to the larger structure of the conceptual categories (GordonFinlayson, 2010). The following section provides further details on how we used the grounded theory approach to analyze and organize the comments, feelings, thoughts, and experiences of SAHFs in our study.

\section{Method}

\section{Participants}

Study participants were primarily recruited through online advertisements placed on the Facebook page of the National AtHome Dad Network and Craigslist in the United States. To participate, fathers had to (a) have children under the age of 18; (b) identify themselves as primary caregivers of their children; and (c) have been primary caregivers to their children for at least 4 months in the past 6 years. Primary caregiver was defined as primarily providing childcare duties during this period, often while a spouse worked. Most fathers indicated that they were unemployed or not working full-time. The criteria for inclusion in this study were more liberal than the Census definition of a SAHF and aligned with Livingston's (2014) definition of a SAHF in that we included individuals who were cohabiting as well as married. We also included fathers who reported working for some pay (e.g., Latshaw, 2011), so long as they identified themselves as primary caregivers. Participants who completed the telephone interview received a \$25 gift card in the mail to thank them for their participation in the study.

Of the 31 individuals who indicated interest, five did not complete the telephone interview and one was excluded because data was missing due to a technical error. The final sample was 25 SAHFs $(M=38.04$ years, $S D=5.77$, age range: $28-48)$ in the U.S. Most were married $(n=23)$, one lived with a female partner, and one lived with a male partner. Seventy-five percent of study participants were White $(n=18), 16.7 \%$ Hispanic/Latino $(n=4)$, $4.2 \%$ Black $(n=1)$, and $4.2 \%$ other $(n=1)$. Our sample was highly educated: The majority had a college degree or higher (83.3\% or $n=20), 8.3 \%$ had an associate degree $(n=2)$, and another $8.3 \%$ had some college education $(n=2)$. Our sample also reported above average incomes. Approximately 46\% reported an annual household income of $\$ 90,000$ or above $(n=11), 29.2 \%$ reported $\$ 70,000-\$ 89,000(n=7), 16.7 \%$ reported $\$ 50,000-$ $\$ 69,000(n=4)$, and $8.3 \%$ reported $\$ 30,000-\$ 49,000(n=2)$. Over half $(66.7 \%$ or $n=16)$ said that they did not contribute to the household income at all. Three quarters of all the participants reported being a SAHF since the birth of the focal child $(n=18)$. Approximately $50 \%$ of the participants had two children $(n=12)$, $25 \%$ had one child $(n=6), 16.7 \%$ had three children $(n=4)$, and $8.3 \%$ had four children $(n=2)$.

\section{Measures}

We conducted semistructured telephone interviews that lasted approximately 1.5 hours and were audio recorded and transcribed for data analysis. In order to build rapport with participants, we first asked them to tell us about themselves. Introductory questions included a brief summary of employment history and whether changes in employment status were voluntary or involuntary. We probed for reasons behind becoming a primary caregiver, child caregiving arrangements before and after becoming a SAHF, as well as a series of questions regarding changes in their roles and responsibilities around the house, relationship with children, and relationship with spouse or partner upon becoming a SAHF.

Next, we used prompts about traditional gender roles- the father as the breadwinner and mother as the homemaker-to examine what SAHFs thought about these norms today and whether their perceptions of being a breadwinner changed given that they were now in a primary caregiving role. Similarly, we asked whether being a SAHF changed their views on masculinity and other gender role norms. These gender role prompts are consistent with Pleck's (1981) conceptualization of gender role strain and O'Neil, Good, and Holmes's (1995) conceptualization of gender role conflict. Gender role prompts were used in our study to better understand the challenges SAHFs experience as a result of taking on a gender role that could potentially generate psychological conflict and interpersonal strain. We ended the interviews by asking participants to share their families' plans for the future along with any additional comments they wished to make.

\section{Procedures: Coding and Textual Analysis}

Consistent with the grounded theory approach, our coding process began with analyzing small chunks of data, a process known as open coding (Glaser \& Strauss, 1965). We developed four global codes for content analysis: (1) background information on employment status and reasons why men became SAHFs; (2) relationships with spouse or partner and children; (3) gender role norms as they relate to SAHFs' masculinities; and (4) additional information pertaining to social isolation, reactions, and support. We assigned these global codes to SAHFs' interview transcripts and then developed and assigned subcodes that further illuminated SAHFs' perspectives in these areas. As these emerging subcodes (i.e., themes) were identified, we created a codebook that included a list of all the codes. Members of the research team independently coded four to five transcripts at a time. Then, the team met to discuss their coding results, discern previously unrecognized themes and subthemes, integrate existing ones, and reconceptualize emerging themes and subthemes as necessary. Through this iterative process, the team reached consensus on the codes. 


\section{Results}

To follow the flow of the interview, this section begins with descriptions of SAHFs' background information, employment status, and reasons for becoming a SAHF. This is followed by a discussion on how becoming a SAHF affected relationships between SAHFs and their spouse or partner and relationships between SAHFs and their children. For the sake of brevity, we report only overall data for these first two themes. We then devote more attention-including quotes from participants-to SAHFs' perceptions of gender role norms and masculinity, and how these perceptions may have shifted during the transition to becoming a primary caregiver. We conclude by analyzing content related to social isolation and social support. All themes and subthemes from this study are presented in Figure 1.

\section{Reasons for Becoming a SAHF}

Among the 18 SAHFs who provided information on change in employment status, 13 (or $72 \%$ ) reported that the change was voluntary, suggesting that they entered the SAHF role by choice. Only two SAHFs reported that the change in their employment status was involuntary, and three SAHFs reported that the change was both voluntary and involuntary. There were three main reasons why men became SAHFs: (1) financial reasons, (2) employment reasons, and (3) direct caregiving reasons. The majority of men mentioned financial reasons for becoming a SAHF; these included high costs of daycare and their partner's earning potential. A substantial portion of men mentioned employment reasons for becoming a SAHF, such as inflexible work schedules that conflicted with family responsibilities, losing a job, getting tired of a job, lacking job prospects, and relocating due to spouse's or partner's job. A smaller proportion of men reported direct caregiving reasons for becoming a SAHF. They either wanted to directly care for their children, or they and their partner held the belief that at least one parent should stay home to raise the children.

\section{Relationships With Spouse or Partner and Children}

Several themes transpired with respect to changes in relationships with spouse or partner. Interestingly, the most common answer by far was that men did not experience significant changes in their relationships with their spouse or partner as a result of becoming a SAHF. The next most commonly reported relationship change was not having enough alone time to spend with their spouse or partner. SAHFs also mentioned experiencing tension in their relationships with their spouse or partner around how one should perform household chores, feeling guilty for staying home, and sensing resentment from their spouse or partner.

When asked about how becoming a SAHF changed their relationships with their children, men in our study most commonly mentioned that they enjoyed being able to see their children grow and meet certain developmental milestones (e.g., hearing a son speak for the first time, seeing a daughter learn how to dance). They also mentioned being able to spend more time with their children. Overall, SAHFs reported that they were able to build stronger relationships with their children as a result of staying home, and that a stronger father-child relationship allowed for more intimacy and trust between them and their children.

\section{Gender Role Norms and Masculine Identities}

The main focus of our analysis was on masculine gender norms and SAHFs' attitudes toward masculine identities. This section is broken into three subsections in accordance to the following themes: (1) interpretation of traditional masculinities, (2) construction of alternative masculinities, and (3) navigation of the challenges of constructing and maintaining new masculine identities.

Interpretation of traditional masculinities. There were different ways in which SAHFs in our study interpreted traditional masculinities. The majority indicated that they liked participating in traditional masculine activities, such as watching sports, playing sports, drinking beer, exchanging jokes, jamming out with male friends, or listening to heavy metal music during their spare time.

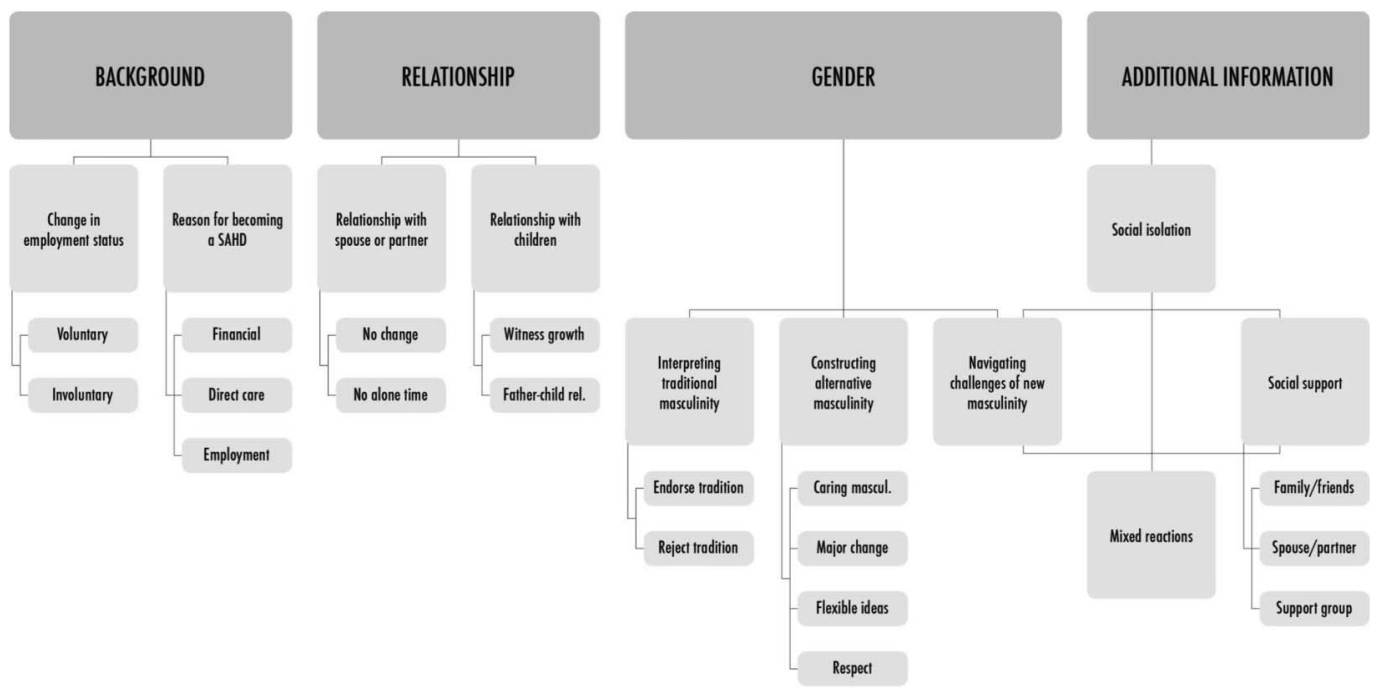

Figure 1. Themes and subthemes that emerged from the coding and textual analysis. 
Two SAHFs alluded to their need to feel independent or respected-characteristics that are salient to traditional masculinities.

I will stay at home, and I'll be the best dad ever, and I'll make it work. And, I do not need any help. . . . It's like you always gotta put on a facade that it's not that big of a deal. . . I I want to prove to everybody that I am good enough, that I can do this, and I'm going to be a damn good man (James).

A guy can do [housework] just as much as a woman should do that or could do that. But, in terms of being a man, just a man, you like to feel respected. . . . I find it difficult if we have people over, and we only talk about my wife's job. . . . I feel that I am ignored and for a man to feel like that, that is a very difficult thing ... That is the thing that I miss, you know? I just call it respect (Mitchell).

SAHFs also endorsed traditional masculinities by expressing their desires to be called Mr. Dad instead of Mr. Mom. This could be understood as SAHFs wanting to align their gender role on their male gender or sex. Five out of six SAHFs who mentioned how they want to be seen by others said that they are doing what a typical SAHF should be doing and that they wish to be called Mr. Dad. The following quotes suggest that SAHFs in our study believe their caregiving roles as fathers are masculine.

When I first started working from home . . . one comment that a lot people made is “Oh, that's so great. You're going to be Mr. Mom." I actually sort of took issue with that and I sort of would respond and I'd say "No, I'm not Mr. Mom. I'm Mr. Dad." That is just my definition of dadness of masculinity (Jackson).

There are still plenty of people that still say "Oh, you're Mr. Mom." No, I'm not Mr. Mom. I am a dad who stays at home and does everything. . . . A dad that's doing this is being a dad. . . I'm not doing this because I'm a mom. I'm doing this because I'm a dad. I'm Mr. Dad (Kevin).

Two other SAHFs reported that they want to be recognized and acknowledged as primary caregivers because, in their view, caring for their children and doing work around the house was a full-time job. James shared an example in which he and his family went to a party where people commented on his dish and his daughters' braids, assuming that his wife had done both. William noted that it was frustrating when people did not view him as a SAHF, mistakenly assuming he was "filling in" or "babysitting" his children, and that their misinterpretations "take away from [his] experience;" he wanted people to know "what's really going on," that is, that he was the primary caregiver of his children.

Interestingly, when asked about traditional male gender roles, a relatively large minority within our sample reported that they rejected traditional masculinities all together. Six SAHFs mentioned that they refuse to subscribe to traditional gender labels because they "don't find them useful." Christopher said that he "kind of reject[ed] that breadwinner thing a long time ago" and was proud that he does not assume traditional gender roles and is a good homemaker. James reported that what other men usually talk about (e.g., snowmobiles, weather) are mundane, "like nothing real," and he gets annoyed when men are expected to talk only about "male type things." In addition, Anthony mentioned that he does not have to "bench press 350 and punch somebody in the face" to feel masculine, and that he married his wife because she is a "strong independent woman."
Construction of alternative masculinities. There were several ways in which study participants constructed alternative masculinities within the caregiving context. These alternative masculinities were embodied by statements that showed how SAHFs incorporated caregiving activities into their masculine identities, for example, arguing that caring for one's children is inherently masculine, holding flexible ideas about what men can do, and developing respect for caregiving and viewing it as legitimate work. Eight out of 19 participants who shared their views on constructing alternative masculinities reported that caring for their children and families is inherently masculine, for example:

It's not that I'm somehow less of a man in my view because I'm not earning the money. ... I have strengths in that, for example, if I need to comfort [my daughter] at night because she's crying . . . if I go to her and I hold her and I rock her and I sing to her or I give her a bottle-to me, that's manliness. That's my definition. . . . It takes a strength when you're exhausted. ... I do not feel any less masculine (Jackson)

Other participants echoed this theme with variation. For example, Edward said parenting his children is being masculine and that "being a dad is macho!" In the same vein, Kenneth argued that men are "stronger" for caring for their children, and Gary mentioned that masculinity and paternal affection are not mutually exclusive. Richard who described himself as coming from a traditionally machismo Spanish background and was once considered a "jock kind of guy" for playing football in high school, discussed how his attitude toward family changed after he became a SAHF; Taking care of his children became "so much more important to me than having people feel like, you know, I'm not masculine." Kyle, who previously was a college football coach and was at the "peak of masculinity in society," shared his experience confronting those who question his masculinity:

What's so masculine about you working at Target? I do not get it ... Why are you more of a man than me because you get a paycheck? It's a very masculine job to take care of your children. . . . It's probably one of the most admirable jobs you can do . . . to take care of your children and put their needs . . . on par with yours.

These accounts suggest that many SAHFs actively incorporate caregiving into their notion of masculinity and hold to the belief that "real men" care for their families and show affection and warmth to their children. The same accounts also point to the potential change in attitudes and masculine identities that accompany becoming a SAHF. Many SAHFs (but not all) spoke of incorporating caregiving into their masculinities as a major shift that resulted from becoming a primary caregiver. For instance, Dennis shared:

When I was growing up, I used to think that masculinity was all about .. . bringing home the bacon and, you know, facial hair, and camping. . . . But as I became a father, I think that masculinity is being there as a father... The whole masculine idea is, you know, you have to be tough, you have to be rough, you know? That all goes out the window and just being a good ... man. A good husband and a good example for my son is what masculinity is to me now.

Furthermore, a number of participants discussed how becoming a SAHF influenced them to have more flexible ideas about what men can do. Two participants in particular suggested that their 
identities have become more fluid and that they toggle between traditional and alternative masculinities, adapting to the social context as needed. Kevin's remarks serve as a good example:

There's that definition of masculinity where I can bench press a Volkswagen. . . I can rip out a tree with my hands ... or there's masculinity where I can have a tea party in a tutu and own it because tea parties are fun.

Four participants mentioned that the transition to being a primary caregiving resulted in shifts in how they related to others emotionally. This is typified once more by Kevin who discussed that becoming the primary caregiver of his daughter helped him became more sensitive to emotions:

I've never been one to shed tears for movies and stuff like that, but after you have a child, you see things differently, you know? It starts getting dusty at certain movies, like your eyes start to water ... then you add a second child and, you know, it's like the same thing. You're like "What's the problem? Why is there dust everywhere?"

Other participants reported flexible ideas about what men can do by referring to shifts in gender norms. For instance, Anthony noted that the more men stay at home, the more women are able to advance their careers. Scott said that society had long ago transitioned away from the breadwinner father and homemaker mother model; the "pendulum has swung back the other direction," and women today have better earning potential, making it possible for men to stay home. Henry alluded to flexible views on masculinities in reference to his relationship with his wife:

I've never had to feel that I had to prove myself to anyone to be, you know, like a manly man or anything like that. I have no problem with my wife being the quote-unquote head of the family. That doesn't bother me at all. If she wants to be the boss, that's fine. ... If this is what I need to do to ... have a good family, then I have no problem with that.

Eight SAHFs reported developing respect for caregiving and viewing it as legitimate work. Carl shared that being a full-time caregiver is harder than expected, and as a result, he gained more respect for those who stay at home with their children:

Being a stay-at-home dad is harder than I thought it was going to be, so I have a little more respect for people who are staying home and how much they accomplish ... especially moms that, you know, have four kids. They're misbehaving and you're like "What the heck? How do you do it? Like I'm just getting by with just one good kid, you know?" So more respect to the people. More acknowledging how hard they're working.

Referring to fellow stay at home parents, Albert said he had "got more respect for them now because I know . . . it's a lot tougher than going to work every day." Similarly, Henry who was a chef before becoming a SAHF said that taking care of his son is harder than working a paid job:

I feel like sometimes that I'm working harder than I was working 80 hours a week at a restaurant. It's nonstop here (referring to caring for his son). There's no hour work week; it's just I'm always on. So I mean, I do not . . . think the work is any less or any easier.

Four other SAHFs echoed the message that full-time caregiving is legitimate work although it is often undercompensated and undervalued. Stephen who has a been a stay-at-home parent for almost a decade said that he is "providing for [his] family" by taking care of his children. Likewise, Lawrence said "Me staying at home taking care of things is my job."

Navigating challenges of constructing and maintaining new masculine identities. SAHFs in our study faced two major challenges in their attempts to construct and sustain alternative masculinities. First, 20 SAHFs identified social isolation as the biggest challenge facing their new family roles and masculine identities. As the following quotes illustrate, incidents of social isolation were most prevalent when SAHFs tried to join local mom groups.

The moms' groups aren't real fond of having dads join their groups. . . . It's like a man trying to join a sorority (Scott).

Some stay-at-home mom groups do not want guys to be involved with any stuff for whatever reason. . . I've been chastised by mothers like "Do you see what your son's doing or your daughter's doing?" (Billy).

There's a local stay-at-home moms' (SAHMs) meet-up that I'll go to every now and then, but I'm the only guy. Even though you're there with a bunch of people, it's still isolating because you're the weird one out of the group (Miles).

Second, 13 SAHFs reported receiving mixed reactions from those around them; these fathers experienced both compliments and criticisms of their status as SAHFs. For example, Henry discussed when he first announced his decision to become a full-time caregiver, both sides of the family "loved it" with the exception of his 90-year-old grandfather who kept asking him "when [he] was going back to work."

Amid these challenges, SAHFs reported three main sources of social support: (1) family and friends; (2) spouse or partner; and (3) local or online SAHF support groups. Six SAHFs reported receiving social support from family members and close friends. Referring to his own father, Anthony said:

Even though my dad was a workaholic ... he was very proud of me. I was a little surprised about this because he calls himself a redneck Republican and yet he was very proud of me for being a stay-at-home dad. He has no problem telling people that I [am] a stay-at-home father. I figured I would get some pushback from him on that, and he never did which was great.

A number of SAHFs also reported that they received concrete support from mothers, in-laws, or sisters-in-law. Such support took the form of childcare and babysitting, especially when SAHFs needed additional help. It is important to note that, compared with other types of support, these functional and practical forms of support mostly came from female members in the family. This suggests that female family members play a key role in helping SAHFs successfully navigate the caregiving domain. The following quotes serve as examples:

[Before] we had to rely on ... my sister-in-law to watch [our][daughter] if we needed somebody. . . . The only person I would have left now to actually take care of [our][daughter] is-during the day if I needed someone—would be my mom (William).

Our closest relative is my mother-in-law who lives about 3 hours away. If we have a really urgent thing . . . my mother-in-law, she drove up and made the arrangements to stay with us (Jackson). 
A lot of times I call my sister at work just to talk to her. I put her on the speakerphone in the car and he'll [his son] talk to her, and we'll talk ... that's where my main support probably is right now when she's [his wife] not there (Henry).

In addition to female family members, SAHFs reported receiving support from friends. For example, Albert shared that his close friends provided indirect support and positive feedback on social media and that envy from them reinforced his sense of fulfillment:

With my daughter . . . 2-3 times a week, we'd be, you know, going to a petting zoo or going to the beach. ... I post pictures and stuff on Facebook just because, you know, I was enjoying the time, and I cannot tell you how many of my friends, male and female, will say "Gosh, I really wish I had the time to do what you're doing with your kids." So, that's probably been the most fun right there.

Five SAHFs reported receiving support from their spouse or partner in the form of praise and help with childcare. Eugene recounted his wife's support in the following way:

You definitely sense some outside like "Really? Dad stays home with the kids? How's that going? That's . . . when you feel like it's just unusual and you feel people being judgy . . . there is definitely, you know, the pressure ... [But][it] kind of goes away somewhat [knowing] that she's [his wife] definitely comfortable with the situation being what it is ... she has been super quick to praise me and kind of let me embrace the role. . . She's let me kind of take in my direction and feel empowered by it. ... I know that she is, in general, approving of what I am doing with the kids, and she feels like the kids are in good hands, and she makes that clear all the time.

Kyle reported that his wife supports him by giving him occasional breaks from taking care of their children:

My wife is very supportive in what I do and she figures out a way to give me some time to myself or she'll just take the kids and do stuff with them, and it's like "Daddy's not home" or something like that.

Finally, nine SAHFs reported receiving support from either a local or online SAHF support group. Anthony notes the important role support groups play in helping him and other SAHFs navigate the challenges of forging new masculine roles and identities amid social isolation:

The most important thing about being a SAHF is to find other SAHFs, and it's the best [and] most important thing. Men have a tendency to not ask for help and finding a support group sounds like you're going to therapy, and who wants to do that? Men are supposed to be strong and take care of themselves and they can handle it all. And, you can, but it doesn't hurt to have somebody who's been in your situation or is in your situation to talk to, to commiserate with, to have a beer with, to make fun of or joke with. That has made all the difference for me and any kind of conversations [I've] had with other SAHFs, that's the key thing. The ones that have had groups, this is the most important thing they've ever done.

Similarly, Eugene highlights the use of different types of social media to connect with other SAHFs and exchange ongoing support:

If I were doing this in a different age, I would feel oh-so-differently if I didn't have the Internet and ability to have a string of like, you know, Twitter people or other dads on Facebook or you know reading blogs ... Just to be able to relate to other people who are in your same circumstances is so important.

\section{Discussion}

This study examined how men's masculine identities are understood and potentially transformed by becoming a SAHF. Consistent with prior research, most of the SAHFs in our study indicated that they voluntarily opted into the role of a primary caregiver (Kramer, Kelly, \& McCulloch, 2013). Our finding that SAHFs had high levels of satisfaction with their caregiving role is also consistent with prior research (Rochlen et al., 2008). SAHFs in our study described numerous benefits to being a primary caregiver, including supporting their spouse's or partner's careers and forming stronger father-child relationships.

One of our major findings is that SAHFs changed their attitudes about care work and masculine identities as a result of engaging in direct, hands-on caregiving. This adds weight to the growing evidence that participating in care work helps men develop caring and nurturing attitudes (Coltrane, 1996; Doucet, 2006; Elliott, 2015; Hanlon, 2012). For example, Coltrane (1996) demonstrated in his qualitative study of dual-earner couples that practicing in child care transforms men and that through interactions with their children, parents construct images of fathers as nurturing and sensitive caregivers. In a similar vein, our findings showed that by engaging in daily care work, SAHFs developed nurturing attitudes and adopted caring masculinities.

We used Elliott's (2015) caring masculinities as our main theoretical framework to elucidate SAHFs' masculine identities. Prior studies have used biosocial theory, social role theory, and symbolic interactionism theory to understand SAHFs' transition to full-time caregiving and their masculine identities (Doucet, 2004; Fischer \& Anderson, 2012; Rochlen et al., 2008). In general, these approaches emphasize how men are socialized to behave in ways that are congruent with traditional masculinities and that deviations from such norms result in consequences. For example, the biosocial theory (Wood \& Eagly, 2002) purports that there are biological and social origins for traditional masculine roles; men are expected to be financial providers of their families, and this gender role is associated with being dominant and assertive. Men who defy such gender role expectations by behaving in traditionally feminine ways are likely to experience prejudice and backlash (Rochlen et al., 2010).

Using grounded theory methodology, we drew upon Elliott's (2015) caring masculinities theory as an alternative framework. Caring masculinities is an appropriate framework for exploring SAHFs' masculinities in our study because SAHFs' reports suggested that they combine caregiving values with their masculine identities. Caring masculinities does not assume that men behave in ways that are congruent with traditional masculinities. Rather, it argues that men are able to rework their masculinities into caring ones by integrating positive emotion, interdependence, and relationality. Caring masculinities is also different from other theories in its implication for men, namely that adopting values of care can enrich men's lives emotionally, physically, and psychologically. Instead of shaming men, caring masculinities argues for encouraging and supporting men's care work to help develop nurturing attitudes and promote gender equality. 
In the following sections, we primarily rely on the caring masculinities theory (Elliott, 2015) and its basic tenets-rejecting traditional masculinity, embracing qualities of care, and recasting traditional masculine values - to interpret our findings and demonstrate that our findings lend support for the theory.

\section{Rejecting Traditional Masculinity}

Most SAHFs discussed ways they challenge, confront, and reject traditional masculinities, but they had different degrees of comfort with the notion of rejecting traditional masculinities. Some pronounced outright rejection, in part because they felt that traditional masculinities lack flexibility and utility in the caregiving context. Others were more ambivalent about rejecting traditional masculinities and discussed how they incorporated traditionally masculine norms into their daily activities and attitudes. This finding is consistent with what previous studies found, that is, SAHFs continue to engage in traditionally masculine activities and publicly display their masculine affiliations (Doucet, 2004; Fischer \& Anderson, 2012).

We argue that some SAHFs may feel ambivalent about rejecting traditional masculinities because they are undergoing shifts in attitudes and beliefs amid a changing gender landscape, and therefore feel the need to simultaneously balance feminine and masculine gender roles without feeling strict allegiance to either. Such feelings of ambivalence are likely to be pronounced among SAHFs who, because of their caregiving roles, have been exposed to a wider range of feminine and masculine experiences. This suggests that SAHFs potentially possess exceptional abilities to fluidly navigate different gender identities, a concept that is consistent with caring masculinities (Elliott, 2015).

Fluid gender identities is a concept that also aligns with Connell's stipulation that masculinity is not a fixed entity embedded in one's body or personality (Connell \& Messerschmidt, 2005). Instead, masculinities are a configuration of practices that are achieved in social action, and as a result, can change based on gender relations in particular social settings (e.g., the father caregiver and mother breadwinner family arrangement). Collectively, these theoretical assertions allow us to draw the conclusion that SAHFs reject traditional masculinities, but they do so in a way that best serves their caregiving roles. That is, SAHFs abandon parts of traditional masculinities that are discrepant with their caregiving values but keep parts that are helpful for sustaining their sense of maleness.

\section{Embracing Affective, Relational, Emotional, and Interdependent Qualities of Care}

Caring masculinities (Elliott, 2015) argues for the importance of valuing positive emotions and relational qualities that likely stem from caring for one's children and proactively engaging in their lives. SAHFs in our study described in positive terms how they underwent personal changes, including becoming more sensitive to emotions, relating to others emotionally, and taking pride in their caregiving role. For example, SAHFs shared their pride when they described that caring for their children is inherently masculine (i.e., "being a dad is macho!", men are stronger for caring, affection and masculinity go hand in hand) - a theme that is similarly echoed in other research (Rochlen et al., 2008). Consistent with caring mas- culinities, our findings demonstrated that SAHFs, as a result of entering a primary caregiver role, experienced changes that allow them to embrace emotion and relational qualities of care and integrate them into their masculine identities.

Developing emotional sensitivity and relational qualities is a concept that is also consistent with the feminist argument that highlights the emotional component of caregiving (Abel \& Nelson, 1990). A group of feminist scholars argue that caregivers engage in care work because it provides fulfillment and meaning that ultimately results in intimate connections with those for whom they provide care (Gilligan, 1982; Miller, 1976). Even so, it is important to note that care work is laborious, has been historically relegated to women, and continues to be seen as "women's work." Women may feel that it is their duty to engage in care work in a way that is not true for most men (Marcotte, 2015).

SAHFs may be an exception to this gender status quo because they acknowledge and demonstrate in their daily interactions with their children that caring is their primary role and responsibility. As a case in point, the majority of SAHFs in our study reported that they deliberately made the choice (instead of being forced into the SAHF role) to stay home and take care of their children. This supports the argument that SAHFs' involvement in their children's care could help reduce gender differences in parenting and has the potential to engender institutional change (Chesley, 2011). It also adds to the growing evidence that the role of the father is expanding beyond that of stereotypic breadwinner and disciplinarian to that of a caregiver and role model for parenting (Yogman \& Garfield, 2016).

Social Isolation and Social Support. We found that SAHFs experienced great difficulties in their quest to develop meaningful relationships with others, especially those outside of their families. Consequently, many SAHFs reported social isolation, a phenomenon that is documented in other studies (Latshaw, 2011; Rushing \& Powell, 2015). SAHFs in our study particularly noted the social isolation that results from being excluded from mothers' play groups, another theme that is consistent with prior research (Latshaw, 2011). Social isolation could be a risk factor for SAHFs in constructing and maintaining caring masculinities because discouragement and loneliness can reinforce the notion that being disengaged from the workforce and being a primary male caregiver are socially illegitimate for men (Smith, 1998).

We also identified that SAHFs rely on family, friends, and support groups for social support. It is noteworthy that female family members - mothers, mother-in-laws, sister-in-laws, female spouse or partner-in particular provided majority of the functional and practical support for SAHFs. This suggests that traditional gender role attitudes and norms (e.g., women are the experts of caregiving) are more or less present in SAHFs' households and that women continue to bear the burden of care work. SAHFs also resorted to support groups which adds to the evidence that SAHFs are increasingly turning to local and online support groups to share their experiences and support each other (Ammari \& Schoenebeck, 2016; Dudley, 2000). Collectively, these findings suggest that social support serves as a protective factor against social isolation and empowers SAHFs to successfully construct and maintain caring masculinities. 


\section{Recasting Traditional Masculine Values}

Caring masculinities (Elliott, 2015) argues for recasting traditional masculine values into relational, interdependent, and careoriented ones. Previous research suggests that SAHFs do not simply trade roles with their spouse or partner, but rather combine elements of masculine and feminine roles (Solomon, 2014b). We found evidence for similar processes in our study as SAHFs, for the most part, sought to define caregiving in a way that incorporated both masculine and feminine roles. For example, a number of SAHFs spoke of how caring for the emotional and physical needs of their children was a means of providing for their families. Burkstrand-Reid (2012) found that some SAHFs redefine what it means to be a provider by being the household manager or engaging in "masculine" housework such as carpentry or house repairs. This argument is based on the assumption that SAHFs reframe traditional masculine values primarily to preserve their masculinity. On the contrary, based on Elliott's (2015) caring masculinities, we argue that SAHFs recast traditional masculine values in their efforts to primarily construct new masculine identities that align with and support their caregiving roles and experiences.

Another important finding is that SAHFs expressed respect for caregiving and acknowledged it as legitimate work as a result of entering the primary caregiver role. Work and employmenttraditionally masculine values - are recast in such a way that caregiving is viewed as interchangeable with, or even more valuable than, paid work and considered respectable labor. Respect for caregiving is also consistent with the principles of feminist theory of care. In particular, Fisher and Tronto (1990) noted that caring is a positive dimension that has been historically and socially devalued by a capitalist and patriarchal order. Caregiving is a process that requires continuous time commitment, detailed knowledge of everyday happenings, and the ability to change care plans flexibility and periodically (Fisher \& Tronto, 1990). SAHFs in our study recognized that these special skills, large amount of resources, and hard work are necessary to care for their children. As a result, they seemed to have come to respect, legitimize, and value the caregiving process.

\section{Study Limitations}

Our study has several limitations that may be important for future research in this area to consider. First, the small sample size and limited demographic characteristics prevent generalization of the results. SAHFs in our study were socioeconomically advantaged and came from households reporting above-average levels of parental education and family income. This is consistent with the demographic characteristics of SAHF households, which tend to have significantly higher levels of education and income than other household types (Kramer et al., 2013). Almost all SAHFs were married and in heterosexual relationships. Although our sample was not socioeconomically diverse, given its size, the sample was fairly racially and ethnically diverse.

Also, the convenience sampling approach and our reliance on only one source (i.e., fathers) for data introduce selection bias and the potential for self-reporting bias. It is quite plausible that men who become SAHFs already hold more flexible ideas about masculine identity than do other men. Future research will benefit from making a distinction between SAHFs who adopt flexible ideas about masculinities before becoming full-time caregivers and
SAHFs who experience change in their views on masculinities as a result of transitioning into the caregiving role. Furthermore, our analyses would have been enhanced by triangulating data from other sources, such as participants' spouses or partners, to gain a more nuanced view of how becoming a primary caregiver influences men's views of masculinities (see e.g., Chesley, 2011).

\section{Conclusion}

The transition to parenthood is a time of great change for men and women. This study examined SAHFs lived experiences through the perspective of caring masculinities and its three tenets (Elliott, 2015). In general, men in our study found satisfaction in their caregiving roles and reported that becoming a SAHF had resulted in mostly positive changes - or, in many cases, few changes at all-in family relationships. This examination of SAHFs' perceptions of gender role norms and masculinity found evidence that norms shift during the transition to being a primary caregiver.

In addition, one of the major findings of this study is the potential change in attitudes and masculine identities men experienced as a result of becoming SAHFs. Men reported that caring for their children helped them become nurturing and sensitive parents. They also mentioned that they were able to better relate to others emotionally and had developed a general respect for caregiving. These findings add to the increasing evidence base that involvement in care work engenders more caring and nurturing attitudes in men (Coltrane, 1996; Doucet, 2006; Hanlon, 2012). They also reinforce the feminist theory of care (Abel \& Nelson, 1990; Fisher \& Tronto, 1990) that highlights caregiving as a challenging yet an invaluable aspect of human life. Furthermore, our findings lend support for Elliott's (2015) argument that when men get involved in care work, they are likely to develop affective and emotional aspects of care.

This study also identified social isolation as one of the main challenges against SAHFs' attempts to construct and maintain caring masculinities. Moreover, the study found that SAHFs have multiple networks of social support-including family members, friends, spouse or partner, and fellow SAHFs-to help them overcome social isolation and related challenges. In particular, SAHFs reported that female family members provided the most amount of functional and practical support, which to some extant suggests that traditional gender roles and practices are still present in SAHF households. The fact that women are proving most of the support at home indicates that care work continues to be a women's burden. In spite of this, our findings collectively suggest that men's gender role norms, attitudes, and masculinities can become more fluid as they become SAHFs and that SAHFs are likely to incorporate masculine and feminine characteristics to develop new masculine identities that best support their caregiving role and experiences.

\section{References}

Abel, E. K., \& Nelson, M. K. (1990). Circles of care: An introductory essay. In E. K. Abel \& M. K. Nelson (Eds.), Circles of care: Work and identity in women's lives (pp. 4-34). Albany, NY: State University of New York.

Ammari, T., \& Schoenebeck, S. (2016, February). "Thanks for your interest in our Facebook group, but it's only for dads:" Social roles of 
stay-at home dads. Paper presented at the Computer Supported Cooperative Work and Social Computing, San Francisco, CA.

Bianchi, S. M., Robinson, J. P., \& Milkie, M. A. (2007). Changing rhythms of American family life: Table 4.1. New York, NY: Russell Sage Foundation.

Burkstrand-Reid, B. A. (2012). Dirty Harry meets dirty diapers: Masculinities, at-home fathers, and making the law work for families. Texas Journal of Women and the Law, 22, 1-44.

Cabrera, N. J., Hofferth, S. L., \& Chae, S. (2011). Patterns and predictors of father-infant engagement across race/ethnic groups. Early Childhood Research Quarterly, 26, 365-375. http://dx.doi.org/10.1016/j.ecresq .2011.01.001

Chesley, N. (2011). Stay-at-home fathers and breadwinning mothers: Gender, couple dynamics, and social change. Gender \& Society, 25, 642664. http://dx.doi.org/10.1177/0891243211417433

Cohn, D., Livingston, G., \& Wang, W. (2014). After decades of decline, a rise in stay-at-home mothers. Retrieved from http://www.pewsocial trends.org/2014/04/08/after-decades-of-decline-a-rise-in-stay-at-homemothers/sdt-2014-04_moms-at-home-0-01/

Coltrane, S. (1996). Family man: Fatherhood, housework, and gender equity. Oxford, UK: Oxford University Press.

Connell, R. W. (1995). Masculinities. Los Angeles, CA: University of California Press.

Connell, R. W. (2000). The men and the boys. Berkeley, CA: University of California Press.

Connell, R. W., \& Messerschmidt, J. W. (2005). Hegemonic masculinity: Rethinking the concept. Gender \& Society, 19, 829-859. http://dx.doi .org/10.1177/0891243205278639

Crompton, R. (2006). Employment and the family: The reconfiguration of work and family life in contemporary societies. Cambridge, UK: Cambridge University Press.

Doucet, A. (2004). "It's almost like I have a job, but I don't get paid:" Fathers at home reconfiguring work, care, and masculinity. Fathering, 2, 277-303. http://dx.doi.org/10.3149/fth.0203.277

Doucet, A. (2006). Do men mother? Fathering, care, and domestic responsibility. Toronto, Canada: University of Toronto Press.

Doucet, A., \& Merla, L. (2007). Stay-at-home fathering: A strategy for balancing work and home in Canadian and Belgian families. Соттиnity, Work \& Family, 10, 455-473. http://dx.doi.org/10.1080/ 13668800701575101

Dudley, J. R. (2000). Confronting stigma within the services system. Social Work, 45, 449-455. http://dx.doi.org/10.1093/sw/45.5.449

Dunn, M. G., Rochlen, A. B., \& O’Brien, K. M. (2011). Employee, mother, and partner: An exploratory investigation of working women with stayat-home fathers. Journal of Career Development, 40, 3-22. http://dx.doi .org/10.1177/0894845311401744

Elliott, K. (2015). Caring masculinities: Theorizing an emerging concept. Men and Masculinities, 19, 240-259. http://dx.doi.org/10.1177/ 1097184x15576203

Ferree, M. M. (1994). Negotiating household roles and responsibilities: Resistance, conflict and change. In M. Stevenson (Ed.), Gender roles through the life span: A multidisciplinary perspective (pp. 203-221). Muncie, IN: Ball State University Press.

Fine, M., \& Glendinning, C. (2005). Dependence, independence or interdependence? Revisiting the concepts of 'care' and 'dependency'. Ageing and Society, 25, 601-622. http://dx.doi.org/10.1017/ S0144686X05003600

Fischer, J., \& Anderson, V. N. (2012). Gender role attitudes and characteristics of stay-at-home and employed fathers. Psychology of Men \& Masculinity, 13, 16-31. http://dx.doi.org/10.1037/a0024359

Fisher, B., \& Tronto, J. (1990). Toward a feminist theory of caring. In E. K. Abel \& M. K. Nelson (Eds.), Circles of care: Work and identity in women's lives (pp. 35-62). Albany, NY: State University of New York.
Freitag, M. (2004). Gender-role conflict. In M. S. Kimmel \& A. Aronson (Eds.), Men and masculinities: A social, cultural, and historical encyclopedia (pp. 348-350). Santa Barbara, CA: ABC-CLIO.

Galley, J. (2014). Stay-at-home mothers through the years. U.S. Bureau of Labor Statistics Monthly Labor Review. Retrieved from http://www.bls .gov/opub/mlr/2014/beyond-bls/stay-at-home-mothers-through-theyears.htm

Garnets, L., \& Pleck, J. (1979). Sex role identity, androgyny, and sex role transcendence: A sex role strain analysis. Psychology of Women Quarterly, 3, 270-283. http://dx.doi.org/10.1111/j.1471-6402.1979 .tb00545.x

Gerson, K. (1993). No man's land: Men's changing commitments to family and work. New York, NY: Basic Books.

Gilligan, C. (1982). In a different voice: Psychological theory and women's development. Cambridge, MA: Harvard University Press.

Glaser, B. G., \& Strauss, A. L. (1965). The discovery of grounded theory: Strategies for qualitative research. Chicago, IL: Aldine.

Gordon-Finlayson, A. (2010). QM2: Grounded theory. In M. Forrester (Ed.), Doing qualitative research in psychology: A practical guide. London, UK: SAGE.

Hanlon, N. (2012). Masculinities, care and equality: Identity and nurture in men's lives. Basingstoke, UK: Palgrave Macmillan.

hooks, b. (2004). The will to change: Men, masculinity, and love. New York, NY: Atria Books.

Jones, J., \& Mosher, W. D. (2013). Fathers' involvement with their children: United States, 2006-2010. National Health Statistics Reports, $71,1-21$.

Kimmel, M. S. (1993). What do men want? Harvard Business Review, 71, $50-59$.

Kramer, K. Z., Kelly, E. L., \& McCulloch, J. B. (2013). Stay-at-home fathers: Definition and characteristics based on 34 years of CPS data. Journal of Family Issues, 36, 1651-1673. http://dx.doi.org/10.1177/ $0192513 X 13502479$

Latshaw, B. A. (2011). Is fatherhood a full-time job? Mixed methods insights into measuring stay-at-home fatherhood. Fathering, 9, 125-149. http://dx.doi.org/10.3149/fth.0902.125

Lewis, J. (1992). Gender and the development of welfare regimes. Journal of European Social Policy, 2, 159-173. http://dx.doi.org/10.1177/ 095892879200200301

Livingston, G. (2014). Growing number of dads home with the kids. Retrieved from http://www.pewsocialtrends.org/2014/06/05/growingnumber-of-dads-home-with-the-kids/st-2014-06-05-stay-at-home-dads04/

Livingston, G., \& Parker, K. (2011). A tale of two fathers: More are active, but more are absent. Washington, DC: Pew Research Center

Marcotte, A. (2015, January 6). Even when they don't have jobs, men do less housework than women. Slate. Retrieved from http://www.slate .com/blogs/xx_factor/2015/01/06/gender_and_housework_even_men_ who_don_t_work_do_less_than_women.html

Merla, L. (2008). Determinants, costs, and meanings of Belgian stay-athome fathers: An international comparison. Fathering, 6, 113-132. http://dx.doi.org/10.3149/fth.0602.113

Miller, J. B. (1976). Toward a new psychology of women. Boston, MA Beacon Press.

Moen, P. S., \& Sweet, S. (2003). Time clocks: Couples' work hour strategies. In P. Moen (Ed.), It's about time: Couples and careers (pp. 18-34). Ithaca, NY: Cornell University Press.

National Academies of Sciences, Engineering, and Medicine. (2016). Parenting matters: Supporting parents of children ages $0-8$. Washington, DC: The National Academies Press.

O’Neil, J. M., Good, G. E., \& Holmes, S. (1995). Fifteen years of theory and research on men's gender role conflict: New paradigms for empirical research. In R. F. Levant \& W. S. Pollack (Eds.), A new psychology of men (pp. 164-206). New York, NY: Basic Books. 
Parker, K., \& Wang, W. (2013). How mothers and fathers spend their time. Retrieved from http://www.pewsocialtrends.org/2013/03/14/chap.-4how-mothers-and-fathers-spend-their-time/

Pleck, J. H. (1981). The myth of masculinity. Cambridge, MA: MIT Press. Pleck, J. H. (1995). The gender role strain paradigm: An update. In R. F. Levant \& W. S. Pollack (Eds.), A new psychology of men (pp. 11-32). New York, NY: Basic Books.

Pleck, J. H., Sonenstein, F. L., \& Ku, L. C. (1993). Masculinity ideology and its correlates. In S. Oskamp \& M. Costanzo (Eds.), Gender issues in social psychology (pp. 85-110). Newbury Park, CA: Sage.

Potuchek, J. L. (1997). Who supports the family? Gender and breadwinning in dual-earner marriages. Stanford, CA: Stanford University Press.

Raley, S. B., Mattingly, M. J., \& Bianchi, S. M. (2006). How dual are dual-income couples? Documenting change from 1970 to 2001. Journal of Marriage and the Family, 68, 11-28. http://dx.doi.org/10.1111/j $.1741-3737.2006 .00230 . x$

Rochlen, A. B., McKelley, R. A., \& Whittaker, T. A. (2010). Stay-at-home fathers' reasons for entering the role and stigma experiences: A preliminary report. Psychology of Men \& Masculinity, 11, 279-285. http://dx .doi.org/10.1037/a0017774

Rochlen, A. B., Suizzo, M., McKelley, R. A., \& Scaringi, V. (2008). "I'm just providing for my family:" A qualitative study of stay-at-home fathers. Psychology of Men \& Masculinity, 9, 193-206. http://dx.doi.org/ 10.1037/a0012510

Rushing, C., \& Powell, L. (2015). Family dynamics of the stay-at-home father and working mother relationship. American Journal of Men's Health, 9, 410-420. http://dx.doi.org/10.1177/1557988314549414

Smith, C. D. (1998). "Men don't do this sort of thing:" A case study of the social isolation of househusbands. Men and Masculinities, 1, 138-172. http://dx.doi.org/10.1177/1097184X98001002002

Solomon, C. R. (2014a). "I feel like a rock star:" Fatherhood for stay-athome fathers. Fathering, 12, 52-70. http://dx.doi.org/10.3149/fth .1201 .52

Solomon, C. R. (2014b). "After months of it, you just want to punch someone in the face:" Stay-at-home fathers and masculine identities. Michigan Family Review, 18, 23-38.

Strauss, A., \& Corbin, J. (1990). Basics of qualitative research: Grounded theory procedures and techniques. Newbury Park, CA: Sage.

Thébaud, S. (2010). Masculinity, bargaining, and breadwinning: Understanding men's housework in the cultural context of paid work. Gender \& Society, 24, 330-354. http://dx.doi.org/10.1177/0891243210369105
Thompson, E. H., \& Pleck, J. H. (1995). Masculinity ideologies: A review of research instrumentation on men and masculinities. In R. Levant \& W. Pollack (Eds.), A new psychology of men (pp. 129-163). New York, NY: Basic Books.

Tichenor, V. J. (2005). Earning more and getting less: Why successful wives can't buy equality. Rutgers, NJ: Rutgers University Press.

Ungerson, C. (2006). Gender, care, and the welfare state. In K. Davis, M. Evans, \& J. Lorber (Eds.), Handbook of gender and women's studies (pp. 272-286). London, UK: Sage. http://dx.doi.org/10.4135/ 9781848608023.n16

U.S. Bureau of Labor Statistics. (2014). Women in the labor force: A databook. Retrieved from http://www.bls.gov/opub/reports/womensdatabook/archive/womenlaborforce_2013.pdf

U.S. Bureau of Labor Statistics. (2015a). American time use survey: 2014 results (Report No. USDL-15-1236). Retrieved from http://www.bls .gov/news.release/pdf/atus.pdf

U.S. Bureau of Labor Statistics. (2015b). Average minutes per day men and women spend in household activities. Retrieved from http://www.bls .gov/tus/charts/household.htm

U.S. Bureau of Labor Statistics. (2016). Economic news release: Employment characteristics of families summary. Retrieved from http://www .bls.gov/news.release/famee.nr0.htm

U.S. Census Bureau. (2015). America's families and living arrangements. Retrieved from https://www.census.gov/hhes/families/data/families .html

Wood, W., \& Eagly, A. H. (2002). A cross-cultural analysis of the behavior of women and men: Implications for the origins of sex differences. Psychological Bulletin, 128, 699-727.

Yogman, M., \& Garfield, C. F. (2016). Fathers' roles in the care and development of their children: The role of pediatricians. Pediatrics, 138 e1-e15. http://dx.doi.org/10.1542/peds.2016-1128

Zimmerman, T. S. (2000). Marital equality and satisfaction in stay-at-home mother and stay-at-home father families. Contemporary Family Therapy, 22, 337-354. http://dx.doi.org/10.1023/A:1007816725358

Received April 14, 2016

Revision received August 24, 2016

Accepted September 8, 2016 